\title{
PEMENUHAN KEBUTUHAN AKTIVITAS DAN LATIHAN ROM (RANGE OF MOTION) PADA ASUHAN KEPERAWATAN PASIEN STROKE NON HEMORAGIK
}

\author{
Miming Oxyandi ${ }^{1}$, Anggun Sri Utami ${ }^{2}$ \\ Program Studi DIII Keperawatan, STIKES ‘Aisyiyah Palembang ${ }^{1,2}$ \\ miming@stikes-aisyiyah-palembang.ac.id ${ }^{1}$ \\ anggunanggita@gmail.co.id ${ }^{2}$
}

\begin{abstract}
ABSTRAK
Latar belakang: Stroke non hemoragik adalah suatu penyakit yang diawali dengan terjadinya serangkaian perubahan dalam otak karena terhambatnya atau berhentinya suplai darah ke otak karena adanya sumbatan. Pasien stroke non hemoragik pada umunya akan mengalami gangguan sensoris dan motoris yang mengakibatkan gangguan keseimbangan termasuk kelemahan otot, serta hilangnya koordinasi, hilangnya kemampuan keseimbangan tubuh dan postur (hemiparesis). Tujuan: Membandingkan kedua masalah keperawatan Stroke Non Hemoragik kedua pasien dalam pemenuhan kebutuhan aktivitas dan latihan. Metode: Jenis penelitian deskriptif analitik dengan pendekatan studi kasus untuk mengeksplorasi masalah asuhan keperawatan pasien stroke non hemoragik dalam pemenuhan kebutuhan aktivitas dan latihan. Subjek dalam studi kasus ini dua pasien dengan inisial Ny.N yang berusia 62 tahun dan pasien kedua dengan inisial Ny.M yang berusia 46 tahun, Asuhan keperawatan dilakukan diruang penyakit dalam disalah satu rumah sakit Swasta kota Palembang. Sedangkan proses pengambilan asuhan keperawatan dari tanggal 24 s/d 26 Mei 2019. Analisa data yang digunakan dalam studi kasus ini adalah analisis deskriptif yang digunakan untuk menganalisis data dengan cara mendeskripsikan data yang terkumpul untuk membuat suatu kesimpulan yang disajikan secara tekstular/narasi. Hasil: Pengkajian mendapatkan data bahwa Ny.N tidak bisa menggerakan seluruh badannya, pasien hanya berbaring. Sedangkan Ny.M tidak bisa menggerakan tangan dan kaki kirinya. Intervensi keperawatan berfokus utama diagnose hambatan mobilitas fisik memiliki tujuan meningkatan kekuatan otot, pasien berpartisipasi dalam aktivitas fisik. Implementasi keperawatan Terdapat perbedaan hasil implementasi keperawatan pada Ny. Tidak terdapat peningkata kekuatan otot dikarena kondisi kesadaran samnolen sedangkan Ny.M peningkatan kekuatan otot pada ekstremitas atas menjadi skala 6 dan ekstremitas bawah skala 4. Saran: diharapakan ada jadwal rehabilitasi terpadu yang terinteritas antara perawat, fisioterapi dan keluarga untuk mencegah tidak terjadi kontraktur ataupun atrofi otot.
\end{abstract}

Kata kunci: Askep, Stroke Non Hemoragik, Kebutuhan aktivitas, latihan

\begin{abstract}
Background: Background: Non-hemorrhagic stroke is a disease that begins with a series of changes in the brain due to obstruction or cessation of blood supply to the brain due to blockages. Non-hemorrhagic stroke patients in general will experience sensory and motor disturbances that result in impaired balance including muscle weakness, as well as loss of coordination, loss of body balance and posture (hemiparesis). Objective: Comparing the two non-hemorrhagic stroke nursing problems of the two patients in meeting their activity and exercise needs. Method: This type of analytic descriptive research with a case study approach to explore the problem of nursing care in patients with non-hemorrhagic stroke in meeting the needs of activities and exercises. Subjects in this case study were two patients with the initials
\end{abstract}


of Mrs. N who was 62 years old and the second patient with the initials of Mrs. M who was 46 years old. Nursing care was carried out in the internal medicine room at one of the Palembang Private Hospital. While the process of taking nursing care from 24 to 26 May 2019. Analysis of the data used in this case study is a descriptive analysis that is used to analyze data by describing the data collected to make a conclusion presented textually / narratively. Results: The study obtained data that Ny.N could not move her entire body, the patient just lay down. Whereas Mrs. M. could not move her left hand and foot. Nursing interventions focus primarily on diagnosing obstacles to physical mobility with the aim of increasing muscle strength, as patients participate in physical activity. Nursing implementation There are differences in the results of nursing implementation in Ny. There is no increase in muscle strength due to the condition of consciousness of Samnolen, whereas Mrs. increased muscle strength in the upper limb to scale 6 and lower limb scale 4. Suggestion: an integrated rehabilitation schedule between nurses, physiotherapists and families to prevent no contractions or atrophy is expected. muscle.

Keywords: Askep, Non Hemorrhagic Stroke

\section{PENDAHULUAN}

Menurut World Health Organization (WHO) stroke adalah suatu gangguan fungsi neurologis akut yang disebabkan oleh gangguan peredaran darah dan terjadi secara mendadak (dalam beberapa detik) atau setidak-tidaknya secara cepat (dalam beberapa jam) dengan gejala-gejala dan tanda-tanda yang sesuai dengan daerah otak terganggu (Erlita, 2017). Selain itu stroke juga merupakan etiologi kecacatan jangka panjang nomor satu di dunia, stroke dapat menimbulkan kecacatan bagi penderita yang mampu bertahan hidup, salah satunya adalah ketidakmampuan perawatan diri akibat kelemahan pada ekstremitas dan penurunan fungsi mobilitas yang dapat menghambat pemenuhan aktivitas kehidupan sehari-hari (AKS). (Septiyani, 2017).

Berdasarkan data World Health Organization (WHO) tahun 2016 diperkirakan 5,5 juta orang meninggal akibat stroke dan diperkirakan tahun 2030 penyakit jantung dan stroke menjadi etiologi utama kematian di dunia. Stroke awalnya cenderung menyerang usia diatas 40 tahun, namun kini stroke juga telah menyerang orang usia yang lebih muda, dan setiap tahun terdapat 15 juta orang di seluruh dunia menderita stroke. Menurut
American Heart Association (AHA), di Amerika Serikat diperkirakan terdapat 3 juta penderita stroke pertahun dengan 500.000 kasus baru. Angka kematian penderita stroke di Amerika Serikat masih cukup tinggi yaitu 50-100 per 100.000 penderita pertahun. Sedangkan stroke semakin meningkat di Indonesia dan merupakan beban Negara akibat disabilitas yang ditimbulkannya. Prevalensi stroke di Indonesia berdasarkan wawancara sebesar 8,3\% pada tahun 2015 dan meningkat menjadi $12,1 \%$ pada tahun 2017 (Ghani, 2017).

Menurut hasil Riset Kesehatan Dasar Kemenkes RI tahun 2018, Jumlah penderita penyakit Stroke di Indonesia tahun 2018 berdasarkan diagnosis tenaga kesehatan (Nakes) diperkirakan sebanyak 1.236.825 orang $(0,7 \%)$, sedangkan berdasarkan diagnosis Nakes atau gejala diperkirakan sebanyak 2.137.941 orang $(12,1)$. Berdasarkan diagnosis Nakes maupun gejala, provinsi Sumatera Selatan memiliki estimasi jumlah penderita Stroke sebanyak 87.676 orang $(16,0 \%)$ dan 49.865 orang (9,1\%) (RIKESDAS RI, 2018). Penelitian Misbach dan Wendra (2017) di 28 rumah sakit di Indonesia terhadap 2.065 pasien stroke, sebagian besar pasien stroke yang dirawat di rumah sakit dalam penelitian ini 
berada pada kelompok usia 45-65 tahun. Stroke pada dewasa muda dan usia tua masing-masing $12,9 \%$ dan $35,8 \%$.

Stroke merupakan penyakit atau gangguan fungsional otak akut fokal maupun global akibat terhambatnya aliran darah keotak karena perdarahan ataupun sumbatan. Jenis stroke yang paling banyak dengan angka kejadian $88 \%$ adalah Stroke Non Hemoragik atau iskemik atau infark karena sumbatan. Pada stroke iskemik, aliran darah keotak terhenti karena aterosklerosik atau bekuan darah yang telah menyumbat suatu pembuluh darah, melalui proses aterosklerosis. Hal ini tentu sangat berdampak pada kesehatan klien (Junaidi, 2012).

Stroke non hemoragik merupakan suatu gangguan pada otak karena terhentinya atau tersumbatnya aliran darah ke otak akibat dari iskemik, trombosis, emboli dan penyempitan lumen (Irfan, 2010). Menurut Hopkins (2013), pada umunya pasien stroke non hemoragik akan mengalami gangguan sensoris dan motoris yang mengakibatkan gangguan keseimbangan termasuk kelemahan otot, serta hilangnya koordinasi, hilangnya kemampuan keseimbangan tubuh dan postur (Hemiparesis). Keadaan hemiparesis merupakan salah satu faktor yang menjadi penyebab hilangnya mekanisme refleks postural normal, seperti mengontrol siku untuk bergerak, mengontrol gerak kepala untuk keseimbangan, rotasi tubuh untuk gerak-gerak fungsional pada ekstremitas (Agusman dkk, 2017).

Hemiparesis disebabkan oleh lesi di saluran kortikospinal dan gangguan pada bagian kortikospinal kanan maka akan menyebabkan ganguan atau hemiparesis pada bagian kiri dari tubuh begitu sebaliknya sehingga berakibat terjadinya hambatan mobilitas. Kondisi tersebut akan mengakibatkan pada pasien yakni mengalami defisit dalam melakukan aktivitas. Aktivitas adalah suatu keadaan untuk bergerak dalam memenuhi kebutuhan hidup. Pasien dengan stroke non hemoragik memerlukan rehabilitasi agar dapat menjalankan aktivitas secara normal (Harsono, 2015).

Rehabilitasi yang bisa dilakukan pada pasien stroke non hemoragik selain terapi medikasi atau obat-obatan yaitu dilakukan fisioterapi atau latihan seperti; latihan beban, latihan keseimbangan, latihan resistansi, hydroteraphy, dan latihan rentang gerak atau Range Of Motion (ROM). Latihan pergerakan bagi penderita stroke merupakan prasarat bagi tercapainya kemandirian pasien, karena latihan gerak akan membantu secara berangsur-angsur fungsi tungkai dan lengan kembali atau mendekati normal, dan menderita kekuatan pada pasien tersebut untuk mengontrol aktivitasnya sehari-hari dan dampak apabila tidak diberi rehabilitasi ROM yaitu dapat menyebabkan kekakuan otot dan sendi, aktivitas sehari-hari dari pasien dapat bergantung total dengan keluarga, pasien sulit untuk memenuhi kebutuhan sehari-hari (Oliviani, 2017).

Menurut penelitian yang dilakukan Jung \& Lee (2014) selain terapi rehabilitasi ROM yang sering dilakukan baik unilateral maupun bilateral, terdapat alternatif terapi lainnya bisa diterapkan dan dikombinasikan serta diaplikasikan pada pasien stroke untuk meningkatkan status fungsional sensori motorik dan merupakan intervensi. Sedangkan penelitian Irawati (2016) dengan sampel pasien Strok Non Hemoragik yang berjumlah 24 pasien. Hasil dari penilitian adalah bahwa ada pengaruh latihan ROM terhadap peningkatan kekuatan otot ekstremitas atas.

Pasien strok non hemoragik memerlukan perawatan khusus agar tidak terjadi komplasi selebih lanjut. Perawat memiliki peranan penting dalam memberikan pelayanan kesehatan. Salah satu peran penting seorang perawat adalah sebagai Educator, dimana pembelajaran merupakan dasar dari Health Education yang berhubungan dengan semua tahap kesehatan dan tingkat pencegahan. Dalam memberikan pelayanan kesehatan kepada keluarga, perawat dapat menekankan pada tindakan keperawatan yang berorientasi 
pada upaya promotif dan preventif. Maka dari itu, peranan perawat memberikan pendidikan kesehatan pada klien dan keluarga dalam hal pencegahan penyakit, pemulihan dari penyakit, memberikan informasi yang tepat tentang kesehatan stroke non hemoragic (Sutrisno, 2013).

Masalah keperawatan yang ditemukan pada pasien yang mengalami stroke, diantaranya resiko peningkatan tekanan intrakranial, perubahan perfusi jaringan otak dan ketidakefektifan bersihan jalan nafas yang mengakibatkan kebutuhan dasar oksigenasi terganggu yang diakibatkan oleh stroke, lalu mengakibatkan hambatan mobilitas fisik yang menunjukan bahwa kebutuhan aktivitasnya terganggu, akibat dari hambatan mobilitas fisik pada pasien stroke akan membuat masalah baru oleh karena itu muncul masalah resiko gangguan integritas kulit dan defisit perawatan diri kebutuhan dasar yang terganggu adalah kebutuhan rasa aman nyaman, kerusakan komunikasi verbal merupakan salah satu akibat dari kurangnya kebutuhan dasar oksigenasi yang terganggu yang mengakibatkan kurangnya oksigen ke pembuluh darah otak yang di sebabkan oleh stroke (Muttaqin, 2011).

Dengan tingginya angka kejadian stroke dan banyaknya masalah keperawatan yang ditimbulkan beserta komplikasinya, maka diperlukan peran perawat sebagai care giver dalam memberikan asuhan keperawatan. Berdasarkan studi pendahuluan yang dilakukan ditempat penelitian diperoleh informasi dari hasil wawancara dan observasi didapat permasalah pemenuhan kebutuhan aktivitas dan latihan pada pasien Stroke Non Hemoragik serta informasi rekam medis Rumah Sakit pengunjung dengan penyakit Stroke Non Hemoragik di ruang rawat Inap penyakit dalam pada tahun 2016 tercatat sebanyak 308 jiwa, tahun 2017 sebanyak 130 jiwa dan tahun 2018 sebanyak 133 jiwa.

Dari uraian di atas, sebagai perwujudan peran serta perawat dalam meningkatkan mutu derajat kesehatan melalui upaya preventif, promotif, kuratif dan rehabilitatif. Peneliti ingin memperoleh pengalaman nyata yang lebih dalam melakukan pemenuhan kebutuhan dasar pada pasien dengan gangguan sistem neurologi: stroke non hemoragik.

\section{METODE PENELITIAN}

Jenis penelitian ini adalah deskriptif analitik dengan menggunakan pendekatan studi kasus untuk mengeksplorasi masalah asuhan keperawatan meliputi pengkajian, diagnosis keperawatan, perencanaan, pelaksanaan, dan evaluasi pada pasien stroke non hemoragik dalam pemenuhan kebutuhan aktivitas dan latihan.

Subjek dalam studi kasus ini adalah pasien Stroke Non Hemoragik, adapun sampel penelitian yang diteliti berjumlah dua pasien dengan Kasus 1 berinisial Ny.N yang berusia 62 tahun dan pasien kedua dengan inisial Ny.M yang berusia 46 tahun, dengan tujuan dapat membandingkan masalah keperawatan Stroke Non Hemoragik. Asuhan keperawatan dilakukan pada dua pasien diruang penyakit dalam disalah satu rumah sakit Swasta kota Palembang, Asuhan ini dilakukan dimulai dari kegiatan penyusunan proposal, pengumpulan data, dilanjutkan dengan pengolahan hasil serta penulisan laporan penelitian dari bulan Maret s/d Juli 2019. Sedangkan proses pengambilan asuhan keperawatan dari tanggal 24 s/d 26 Mei 2019.

Prosedur penelitian ini dilakukan setelah mendapat persetujuan dari pihak rumah sakit lalu mengajukan persetujuan penelitian (informed consent) kepada kedua subjek dengan memperhatikan prinsip etika yang meliputi hak untuk self determination; hak terhadap privacy dan dignity; hak terhadap anonymity dan confidentiality. Lalu dilanjutkan dengan proses asuhan keperawatan pertama melakukan pengkajian pada kedua pasien terlebih dahulu, kemudian dilanjutkan dengan penentuan diagnosa dan penyusunan rencana keperawatan yang akan dilakukan dan terakhir melakukan evaluasi keperawatan dari tindakan yang diterapkan 
dengan format SOAP hingga proses asuhan keperawatan berakhir.

Metode pengumpulan data studi kasus ini mengunakan teknik :

a. Wawancara

b. Observasi

c. Pemeriksaan fisik (dengan pendekatan IPPA : inspeksi, palpasi, perkusi, auskultasi) pada sistem tubuh Pasien.

d. Studi dokumentasi (hasil dari pemerikasaan diagnostik)

Pemeriksaan diagnostik adalah pemeriksaan yang dilakukan untuk menegakkan suatu diagnosis penyakit. Sedangkan Diagnosis merupakan penentuan sifat penyakit atau membedakan satu penyakit dengan yang lainnya.

Alat atau instrumen pengumpulan data menggunakan format pengkajian dengan pendekatan pemeriksaan fisik head to toe, lembar observasi ROM (Range Of Motion) pasif, lembar observasi derajat kekuatan otot dengan penentuan diagnose dengan NANDA, serta format penentuan rencana NIC dan NOC. Analisa data yang digunakan dalam studi kasus ini adalah analisis deskriptif yang disajikan secara tekstular/narasi. Analisa data dilakukan sejak peneliti dilapangan, mengumpulkan data sampai data terkumpul semua, Analisa data dengan cara mengemukakan fakta, selanjutnya membandingkan dengan teori yang ada dan selanjutnya dituangkan dalam opini pembahasan. Teknik analisis yang digunakan dengan cara menarasikan jawaban-jawaban dari penulisan yang diperoleh dari hasil interpretasi wawancara mendalam yang dilakukan untuk menjawab rumusan masalah penulisan. Teknik analisis digunakan dengan cara observasi oleh penulis dan studi dokumentasi yang menghasilkan data untuk selanjutnya dinterpretasikan dan dibandingkan teori yang ada sebagai bahan untuk memberikan rekomendasi dalam intervensi tersebut.

\section{HASIL DAN PEMBAHASAN}

Setelah memberikan asuhan keperawatan pada pasien stroke non hemoragik pada Ny.N dan Ny.M dilakukan pada tanggal 24- 26 Mei 2019. Proses keperawatan mulai dari pengkajian, penentuan diagnose keperawatan, perencanaan, implementasi dan evaluasi.

\section{Pengkajian}

Berdasarkan hasil pengkajian menggunakan pendekatan pemeriksaan fisik head to toe, didapatkan hasil pengkajian sebagai berikut:

\section{Kasus 1 (Ny.N)}

Pengkajian dilakukan pada tanggal 24 Mei 2019. Hasil pengkajian didapatkan Ny.N alasan datang ke Rumah Sakit karena jatuh dari WC, setelah itu seluruh badannya lemah tidak bisa digerakkan. Pasien sebelumnya ada riwayat penyakit stroke dan hipertensi. Hasil pemeriksaan fisik diperoleh data subjektif; Keluarga pasien mengatakan pasien mengalami sesak, seluruh badan pasien tidak bisa bicara dan digerakan dan lama tidak mandi, hanya di lap saja, Pasien hanya bisa makan berbentuk cair yang diberikan dari rumah sakit. Sedangkan data objektifnya; GCS 7 (Somnolen), Suara nafas gurgling, Makanan pasien tampak berbentuk cair/bubur, Kelemahan/sakit saat menelan, Rentang gerak terbatas, Kekuatan otot skala 0, mengalami Hemiparesis. TD: 100/70 mmHg, Nadi: 87 x/menit, RR: 27 $\mathrm{x} / \mathrm{menit}, \mathrm{T}: 36,5 \mathrm{C}$.

\section{Kasus 2 (Ny.M)}

Pengkajian dilakukan pada tanggal 24 Mei 2019. Hasil pengkajian didapatkan pada Ny.M alasan datang ke Rumah sakit yaitu pusing, setelah 2 hari di rumah sakit tangan dan kaki kirinya terasa lemah tidak bisa digerakkan. Hasil pemeriksaan fisik diperoleh data subjektif; pasien mengatakan tangan dan kaki kirinya tidak bisa bergerak hanya berbaring ditempat tidur dan aktifitas sehari-harinya dibantu keluarga dan lama tidak mandi, hanya di lap saja, Pasien hanya bisa makan berbentuk cair yang diberikan dari rumah sakit. Sedangkan data objektifnya; Rentang gerak terbatas, Kekuatan otot skala 5 pada ektrimitas kanan dan skala 3 pada ektrimitas kiri, mengalami Hemiparesis. TD : 140/90 
mmHg. Nadi : $85 \mathrm{x} /$ menit, RR : $20 \mathrm{x} / \mathrm{menit}$ $\mathrm{T}: 36,5 \mathrm{C}$.

Hasil pengkajian dari Ny.N dan Ny.M sulit melakukan aktivitas sehari-hari, serta badanya terasa lemah dan tidak bisa digerakkan. Berdasarkan hasil pemeriksaan laboratorium pada kedua pasien, dapat dilihat pada tabel 1 sebagai berikut.

Tabel 1.

Hasil Pemeriksaan Laboratorium

\begin{tabular}{llccc}
\hline No & $\begin{array}{c}\text { Pemeriksaan } \\
\text { Diagnostik }\end{array}$ & Kasus 1 (Ny.N) & Kasus 2 (Ny.M) & Nilai Normal \\
\hline 1 & Hemoglobin & 17,2 & 15,3 & $14,0-18,0$ \\
\hline 2 & Leokosit & 13,1 & 12,0 & $4,2-11,0$ \\
\hline 3 & Trombosit & 287 & 257 & $150-440$ \\
\hline 4 & Ematokrit & 50,8 & 43,9 & $42,0-52,0$ \\
\hline 5 & Eosinofil & 0,1 & 0,1 & $0-1$ \\
\hline 6 & Basofil & 0,1 & 0,1 & $0-1$ \\
\hline 7 & Neutrofil Batang & 0,0 & 0,0 & $2-6$ \\
\hline 8 & Neutrofil Segmen & 82,1 & 50,4 & $40-60$ \\
\hline 9 & Limfosit & 12,6 & 39,8 & $20,0-50,0$ \\
\hline 10 & Monosit & 5,0 & 3,1 & $2-8$ \\
\hline
\end{tabular}

Pengkajian adalah pemikiran dasar dari proses keperawatan yang bertujuan untuk mengumpulkan informasi atau data tentang klien, agar dapat mengidentifikasi, mengenali masalah-masalah, kebutuhan kesehatan, dan keperawatan klien, baik fisik, mental, sosial dan lingkungan (Effendy, 2013).

Sedangkan pengkajian yang dilakukan pada Ny.N dan Ny.M sesuai dengan teori Menurut Wijaya dan Putri (2015). Pengkajian dengan Stroke Non Hemoragik berupa pengumpulan data umum, keluhan utama, riwayat penyakit, riwayat kesehatan psikososial, riwayat spiritual, pengkajian fisik, dan pemeriksaan diagnostik.

Pada pengkajian keluhan utama saat dikaji, kedua pasien tidak bisa menggerakan tangan dan kakinya. Menurut Arum (2015) komplikasi stroke tidak dapat dihindari adalah adanya gangguan mobilitas fisik. Hal ini menunjukkan bahwa terdapat kesamaan pada teori dan praktik. Sedangkan pada pengkajian riwayat perjalanan penyakit kedua pasien mengatakan Pasien tidak bisa menggerakan tangan kaki nya dan hanya berbaring dan tidak bisa duduk.

Berdasarkan asumsi peneliti terdapat kesamaan bahwa pasien sebelumnya mempunyai riwayat hipertensi dan diabetes mellitus yang menjadi faktor resiko terjadinya stroke. Hasil pengkajian dari Ny.N dan Ny.M sulit melakukan aktivitas sehari-hari, serta badanya terasa lemah dan tidak bisa digerakkan, Pasien mengeluhkan adanya kelemahan pada anggota gerak tubuhnya sehingga kedua pasien mengalami hambatan terhadap mobilitas fisiknya sehingga membutuhkan latihan gerak (ROM) secara rutin untuk meningkatkan kekuatan ototnya sehingga pasien melakukan aktivitas hidup harian (Activities of Daily living atau ADL) dapat terjadi peningkatan kemampuan dalam melakukan aktivitas hidup hariannya.

\section{Diagnosa Keperawatan}

Diagnosa keperawatan adalah keputusan klinik tentang respon individu, 
keluarga dan masyarakat tentang masalah kesehatan aktual atau potensial, dimana berdasarkan pada pendidikan dan pengalamannya, perawat secara akuntabilitas dapat mengidentifikasikan dan memberikan intervensi secara pasti untuk menjaga, menurunkan angka kejadian sakit (Feggin, 2015).
Analisa data dari hasil pengkajian merupakan rumusan dalam menentukan diagnosa keperawatan kepada kedua pasien pada kenyataan untuk kasus Ny.N dan Ny.M. Peneliti menemukan 8 diagnosa, diantaranya 2 diagnosa yang sama dan 6 diagnosa yang berbeda, berikut diagnosa keperawatan yang ditemukan.

Tabel 2.

Diagnosa Keperawatan

\begin{tabular}{|c|c|c|c|}
\hline \multicolumn{4}{|c|}{ MASALAH KEPERAWATAN } \\
\hline No & PASIEN Ny. N & No & PASIEN Ny. M \\
\hline 1. & $\begin{array}{l}\text { Ketidakefektifan bersihan jalan nafas } \\
\text { b.d penumpukan sputum, } \\
\text { menurunnya refleks batuk }\end{array}$ & 1 & $\begin{array}{l}\text { Gangguan mobilitas fisik b.d } \\
\text { hemipare }\end{array}$ \\
\hline 2. & $\begin{array}{l}\text { Gangguan menelan b.d penurunan } \\
\text { fungsi nervus vagus }\end{array}$ & 2 & Konstipasi b.d imobilisasi \\
\hline & $\begin{array}{l}\text { Gangguan mobilitas fisik } \text { b.d } \\
\text { hemipare }\end{array}$ & 3 & $\begin{array}{l}\text { Defisit perawatan diri b.d tirah } \\
\text { baring/mobilitas menurun }\end{array}$ \\
\hline & $\begin{array}{l}\text { Defisit perawatan diri b.d tirah } \\
\text { baring/mobilitas menurun }\end{array}$ & 4 & $\begin{array}{l}\text { Intoleransi aktivitas } \\
\text { kelemahan umum }\end{array}$ \\
\hline & $\begin{array}{l}\text { Gangguan komunikasi verbal b.d } \\
\text { pelemahan sistem muskuloskeletal }\end{array}$ & 5 & - \\
\hline & $\begin{array}{l}\text { Resiko ketidakseimbangan nutrisi } \\
\text { kurang dari kebutuhan tubuh b.d } \\
\text { ketidakmampuan untuk mencerna } \\
\text { makanan, penurunan fungsi nervus } \\
\text { hipoglosus }\end{array}$ & 6 & - \\
\hline
\end{tabular}

Pada kenyataan untuk kasus Ny.N dan Ny.M menemukan 8 diagnosa, diantaranya 2 diagnosa yang sama dan 6 diagnosa. Menurut Gordon (2015) diagnosa keperawatan merupakan masalah kesehatan actual atau potensial dimana perawat, dengan pendidikan dan pengalamannya mampu dan mempunyai izin untuk mengatasinya. Diagnosa keperawatan merupakan penilaian klinik tentang respon individu, keluarga, atau komunitas terhadap masalah kesehatan / proses kehidupan yang actual atau potensial. Diagnosa keperawatan merupakan dasar pemilihan intervensi dalam mencapai tujuan yang telah ditetapkan oleh perawat yang bertanggung jawab (Muhith, 2015). Pada diagnosa keperawatan secara teori penulis mendapatkan 5 diagnosa dari refrensi NANDA yaitu sebagai berikut : Ketidakefektifan perfusi jaringan serebral, kerusakan komunikasi verbal, defisit perawatan diri, kerusakan mobilitas fisik, resiko kerusakan integritas kulit, resiko aspirasi (NANDA, 2015).

Pada pasien satu dan pasien dua memiliki perbedaan, karena pada saat pengkajian tidak ada data yang mendukung untuk merumuskan diagnosa seluruhnya, kedelapan diagnosa yang diangkat memang telah sesuai dengan hasil yang didapatkan 
saat pengkajian, baik secara subjektif maupun objektif dan ketiga diagnosa tersebut sesuai dengan kriteria yang ada dalam perumusan diagnosa. Salah satu diagnosa keperawatan yang muncul yaitu hambatan mobilitas fisik. pada dua pasien studi kasus ini pelaksanaan keperawatan hanya berfokus pada satu masalah keperawatan yaitu masalah hambatan mobilitas fisik dan berfokus pada tindakan ROM pasif.

Sesuai rujukan teori NANDA (2015-2017) bahwa batasan karateristik diagnosa hambatan mobillitas fisik yaitu dyspnea setelah beraktivitas, gangguan sikap berjalan, gerakan lambat, gerakan spastik, gerakan tidak terkordinasi, instabillitas postur, keterbatasan rentang gerak, ketidaknyamanan, melakukan aktivitas lain sebagai pengganti pergerakan, penurunan kemampuan melakukan keterampilan motorik kasar, penurunan waktu reaksi, tremor akibat bergerak. Adapun batasan karateristik yang ditemukan penulis yaitu berfokus pada hambatan mobilitas fisik dengan batasan karateristik seperti gerakan lambat, gerakan spastik, gerakan tidak terkoordinasi, kesulitan membolak balikkan posisi, dan keterbatasan rentang gerak.

Berdasarka asumsi peneliti bahwa diagnosa yang muncul pada pasien satu dan dua yaitu terdapat perbedaan, karena pada saat pengkajian tidak ada data yang mendukung untuk merumuskan diagnosa seluruhnya. Pada pasien satu muncul enam diagnosa di mana sesuai dengan data objektif dan subjektif. Sedangkan pada pasien dua terdapat 4 diagnosa. pada dua pasien studi kasus ini pelaksanaan keperawatan hanya berfokus pada satu masalah keperawatan yaitu masalah hambatan mobilitas fisik dan berfokus pada tindakan ROM pasif. Hal ini karena pasien mengalami hambatan terhadap mobilitas fisiknya sehingga membutuhkan latihan gerak (ROM) secara rutin untuk meningkatkan kekuatan ototnya sehingga pasien melakukan aktivitas hidup harian (Activities of Daily living atau ADL) dapat terjadi peningkatan kemampuan dalam melakukan aktivitas hidup hariannya

\section{Intervensi Keperawatan}

Intervensi keperawatan pada studi kasus ini yang berfokus baik pada kasus 1 maupaun kasus 2 pada diagnose hambatan mobilitas fisik memiliki tujuan setelah dilakukan tindakan keperawatan selama $3 \times 24$ jam diharapkan hambatan mobilitas fisik dapat teratasi dengan kriteria hasil berdasarkan NOC (Nursing Outcomes Clasification): meliputi peningkatan kekuatan otot, pasien berpartisipasi dalam aktivitas fisik tanpa disertai peningkatan tekanan darah, nadi, dan respirasi, mampu mempertahankan atau meningkatan kekuatan otot. Intervensi yang ditentukan pada kasus 1 dan kasus 2 yaitu pertama yang dilakukan kaji kemampuan secara fungsional. Kelemahan otot menyebabkan ketidakseimbangan dan saat berjalan karena gangguan kekuatan otot, keseimbanagan dan koordinasi gerak (Irdawati, 2016).

Intervensi yang kedua yaitu monitor tanda tanda vital untuk mengetahui keadaan pasien. Intervensi yang ketiga yaitu ubah posisi minimal setiap 2 jam, Hal ini sesuai dengan penelitan Zulaikah (2013) pasien yang mengalami keterbatasan untuk mobilisasi akan mengalami bedrest total sehingga berdampak mengalami tekanan. Tulang yang menonjol akan mengalami tekanan yang menyebabkan penurunan suplai darah

pada jaringan akan kekurangan oksigen yang berpotensi mengalami decubitus.

Intervensi yang keempat yaitu ajarkan dan dukung pasien dalam latihan Range Of Motion (ROM) aktif asistif: spherical grip. Hal ini dipilih karena sesuai penelitian Olviani (2017) bahwa ada pengaruh latihan sebanyak 2 kali sehari pagi dan sore dalam 10 menit selama 7 hari berturut turut sehingga terjadi peningkatan kekuatan otot. Pada ekstremitas bawah tetap diberikan ROM aktif, latihan ini diberikan untuk mempertahankan atau meningkatkan kelenturan otot, Hal ini sejalan dengan penelitian Irdawati (2016) bahwa selama 12 hari diberikan latihan ROM terdapat 
perbedaan yang bermakna antara nilai kekuatan otot sebelum dan setelah latihan. Intervensi yang kelima yaitu libatkan keluarga untuk membantu pasien latihan gerak hal ini dengan penelitian Hermawati (2017) bahwa dukungan keluarga sangat diperlukan pasien stroke untuk dapat bertahan dalam menjalani hidup, karena keluarga merupakan bagian terdekat dari pasien. Dukungan keluarga akan membuat pasien stroke merasa dihargai dan diterima, sehingga dapat meningkatkan semangat dan motivasi dalam dirinya.

Menurut Arum (2015) rencana tindakan keperawatan merupakan serangkaian tindakan yang dapat mencapai setiap tujuan khusus. Perencanaan keperawatan meliputi perumusan tujuan, tindakan, dan penilaian rangkaian asuhan keperawatan pada pasien berdasarkan analisis. Sedangkan menurut Feggin (2015) Intervensi keperawatan merupakan tindakan yang dirancang untuk membantu klien dalam beralih dari tingkat kesehatan saat ini ke tingkat yang diinginkan dalam hasil yang diharapkan.

Berdasarkan asumsi peneliti bahwa intervensi yang dibuat apabila latihan diberikan secara berkala dan berkesinambungan diharapkan kekuatan otot meningkat. Pemberian latihan gerak pada masa ini sangat efektif karena masih dalam masa golden period. Secara komprensif rencana keperawatan antara pasien 1 dan pasien 2 terdapat perbedaan, dimana pasien 1 intervensi yang dibuat lebih banyak dan kompleks dibandingkan dengan pasien 2, ini disebabkan karena pasien 1 keadaannya lebih darurat dan penyakit stroke nya sudah lama dibandingkan dengan pasien 2, sehingga perlu penanganan yang lebih cepat dengan di buatnya perencanaan yang komprehensif dalam mengatasi masalah pada pasien 1 diharapkan masalah yang mucul dapat di minimalisasikan. Sedangkan masalah pada pasien 2 dimana penyakit stroke nya baru sehingga intervensi dibuat pun lebih sedikit dibandingkan pasien 1 .

\section{Implementasi Keperawatan}

Implementasi keperawatan adalah serangkaian kegiatan yang dilakukan oleh perawat untuk membantu klien dari masalah status kesehatan yang lebih baik yang menggambarkan kriteria hasil yang diharapkan (Potter \& Perry, 2010).

Implementasi keperawatan studi kasus yang diterapkan oleh peneliti yaitu melaksanakan asuhan keperawatan pada dua pasien dengan diagnosa medis Stroke Non Hemoragik hanya berfokus pada satu masalah keperawatan yaitu masalah hambatan mobilitas fisik dan berfokus pada tindakan ROM pasif. Tindakan ROM pasif ini meliputi fleksi, ekstensi, hiperekstensi, pronasi, dan supinasi. Salah satu tanda dan gejala pada pasien stroke yaitu ada kelemahan pada bagian ekstermitasnya sehingga menurut Potter \& Perry, (2010) penatalaksanaan pasien post stroke yaitu rehabilitasi untuk mencegah kecacatan pada ekstermitasnya seperti latihan rentang gerak yang dilakukan oleh perawat ataupun fisioterapi, latihan rentang gerak dilakukan agar tidak terjadi kontraktur ataupun atrofi otot.

Fokus utama pada intervensi keperawatan studi kasus ini pada diagnosa hambatan mobilitas fisik berhubungan dengan gangguan neuromuscular peneliti menekankan pada pemberian teknik Range Of Motion (ROM) pasif untuk meningkatkan kekuatan otot ekstremitas pada Kasus 1 (Ny.N) mengalami kelemahan anggota tubuh seluruh tubuh dan pada Kasus 2 (Ny.M) yang mengalami kelemahan anggota tubuh bagian kiri. Dari pemberian terapi selama 3 hari dan diberikan 2 kali sehari, didapatkan hasil sebagai berikut, hari pertama pemberian ROM dilakukan 2 kali pagi dan sore pada Ny.N kekuatan otot sebelum latihan kekuatan otot ekstremitas atas dan bawah skala 0 dan kiri skala 0 sedangkan $\mathrm{Ny}$. M kekuatan otot ekstremitas atas dan bawah kiri skala 5 dan kiri skala 3. Terjadi peningkatan kekuatan ototnya pada Ny M. hari kedua belum ada peningkatan kekuatan otot pagi dan sore $\mathrm{Ny}$. N kekuatan otot 
sebelum latihan kekuatan otot ekstremitas atas dan bawah skala 0 dan kiri skala 0 sedangkan Ny.M kekuatan otot ekstremitas atas skala 5 dan ekstremitas atas skala 3 . Terjadi peningkatan satu tingkat skala kekuatan ototnya pada Ny.M.

Pada hari ketiga terdapat peningkatan kekuatan otot pada ekstremitas atas menjadi skala 6 dan ekstremitas bawah skala 4 . Sedangkan pada Ny. Tidak terdapat peningkata kekuatan otot dikarena kondisi kesadaran samnolen. Hari ketiga ini juga melatih dan mengobservasi kembali ROM pasif pada dengan melibatkan keluarga dan keluarga menyatakan akan sering berlatih sendiri dikarena sudah mengetahui cara latihan rentang gerak.

Hasil penelitian Sukmaningrum (2012) dari 20 responden, didapatkan beberapa responden tidak mengalami kenaikan nilai kekuatan otot. Stroke merupakan trauma neurologic akut yang bermanifestasi sebagai perdarahan atau infark otak. Infark otak timbul karena iskemua otak yang lama dan parah dengan perubahan fungsi dan struktur otak yang irreversible. Daerah sekitar infark timbul timbul di daerah penumbra iskemik dimana sel masih hidup tetapi tidak berfungsi. Daerah diluar penumbra akan timbul edema local atau hemiparesis berarti sel masih hidup dan berfungsi. Lamanya pemberian latihan dapat mempengaruhi hasil yang dipeoleh. Pada penelitian ini tampak peningkatan ke kuatan otot pada hari ke 3 pagi setelah latihan tetapi tidak langsung pada hari pertama pemberian latihan. Lama latihan tergantung pada stamina pasien. Terapi latihan yang baik adalah latihan yang tidak melelahkan, durasi tidak terlalu lama.

Berdasarkan asumsi peneliti bahwa pada proses implementasi asuhan keperawatan pada Ny.N dan Ny.M dengan stroke non hemoragik yang telah direncanakan sebelumnya. Terdapat perbedaan hasil implementasi keperawatan pada Ny.N Tidak terdapat peningkatan kekuatan otot dikarena kondisi kesadaran samnolen sedangkan Ny.M peningkatan kekuatan otot pada ekstremitas atas menjadi skala 6 dan ekstremitas bawah skala 4 . Sedangkan secara konferensif Pelakasanaan asuhan keperawatan ini dilakukan sesuai dengan kondisi dan situasi serta menggunakan sarana yang tersedia di ruangan, Pada implementasi mengatur posisi pasien semi fowler tidak dilakukan secara maksimal ini disebabkan karena keterbatasan sarana prasarana yaitu dimana bed tempat tidur pasien tidak bisa diatur untuk posisi 45 derajat, sehingga untuk meminimalisasi terjadinya sesak perawat menganjurkan pasien untuk tidur dengan posisi kepala lebih tinggi dari pada kaki dengan memberikan tumpukan bantal di bawah kepala dan leher. Sehingga secara tidak langsung akan meningkatkan kapasitas paru-paru untuk mengembang, sehingga akan mempermudah pasien untuk bernafas.

\section{Evaluasi Keperawatan}

Evaluasi adalah tahap dimana membandingkan hasil tindakan yang dilakukan dengan kriteria hasil yang sudah ditetapkan dalam perencanaan serta menilai apakah masalah sudah teratasi seluruhnya,hanya sebagian atau belum teratasi (Debora, 2011). Efektivitas tindakan dan pencapaian hasil yang teridentifikasi terus dievaluasi sebagai penilaian status pasien. Evaluasi harus terjadi pada setiap langkah dalam proses keperawatan, serta rencana yang telah dilaksanakan (NANDA, 2015).

Peneliti melaksanakan implementasi berdasarkan implementasi berdasarkan kriteria hasil yang telah di tetapkan. Dalam melaksanakan evaluasi, peneliti mengalami hambatan karena ada beberapa masalah yang belum teratasi. Hasil evaluasi dari diagnosa keperawatan hambatan mobilitas fisik berhubungan dengan gangguan neuromuskuler yang sudah dilakukan selama 3 hari didapatkan hasil pasien berpartisipasi dalam aktivitas tanpa disertai peningkatan tekanan darah, nadi, dan respirasi pada Ny. M. serta terdapat peningkatan kekuatan otot pada ekstremitas atas menjadi skala 6 dan ekstremitas bawah skala 4. Sedangkan pada Ny. Tidak terdapat 
peningkata kekuatan otot dikarena kondisi kesadaran samnolen. Pada hari pertama dan kedua belum ada peningkatan kekuatan otot senigfikat pada hari ketiga terdapat peningkatan skala kekuatan otot hal ini dikarena melibatkan keluarga dalam melaksanakan ROM.

Berdasarkan asumsi peneliti bahwa evaluasi keperawatan pada Kasus 1 (Ny.N) dan Kasus 2 (Ny.M) terdapat kesenjangan hasil evaluasi keperawatan pada Ny.N dimana tidak terdapat peningkatan skala kekuatan otot. Hal ini karena Ny.N keadaannya lebih darurat dan penyakit stroke nya sudah lama dan disertai tingkat kesadaran samnolen. Sedangkan masalah pada Ny.M dimana penyakit stroke nya baru sehingga intervensi dibuat pun lebih sedikit dibandingkan Ny.N. Evaluasi secara konferensif dimana Ny. dengan 6 masalah keperawatan yang muncul hanya 2 masalah keperawatan yang teratasi dan yang lainnya tidak teratasi. Ini disebabkan karena keterbatasan sarana prasarana yang dapat menunjang kesembuhan dan kondisi Ny.N lebih gawat sehingga dalam waktu 3 hari peneliti melakukan asuhan keperawatan masalah keperawatan pada Ny.N belum bisa teratasi seluruhnya. Sedangkan pada Ny.M dengan 4 masalah keperawatan yang muncul seluruhnya dapat teratasi, ini disebabkan karena kondisi penyakit stroke Ny.M baru dialami dan lebih ringan, sehingga dalam waktu 3 hari peneliti melakukan asuhan keperawatan masalah yang muncul dapat teratasi seluruhnya.

\section{KESIMPULAN DAN SARAN Kesimpulan}

Setelah peneliti melaksanakan asuhan keperawatan pada Ny.N dan Ny.M dengan stroke Non Hemoragik, maka peneliti berkesimpulan bahwa :

1. Pengkajian mendapatkan data bahwa Ny.N tidak bisa menggerakan seluruh badannya, pasien hanya berbaring. Sedangkan Ny.M tidak bisa menggerakan tangan dan kaki kirinya.

2. Diagnosa keperawatan ditemukan pada pasien stroke Non Hemoragik Ny.N yaitu : bersihan jalan nafas tidak efektif, gangguan mobilitas fisik, defisit perawatan diri, gangguan komunikasi verbal, gangguan menelan dan resiko ketidakseimbangan nutrisi kurang dari kebutuhan tubuh sedangkan pada Ny.M yaitu : gangguan mobilitas fisik, defisit perawatan diri, konstipasi, dan intoleransi aktivitas.

3. Intervensi keperawatan pada studi kasus ini yang berfokus utama diagnose hambatan mobilitas fisik memiliki tujuan setelah dilakukan tindakan keperawatan selama $3 \times 24$ jam diharapkan hambatan mobilitas fisik dapat teratasi dengan kriteria hasil berdasarkan NOC (Nursing Outcomes Clasification): meliputi peningkatan kekuatan otot, pasien berpartisipasi dalam aktivitas fisik.

4. Implementasi keperawatan Terdapat perbedaan hasil implementasi keperawatan pada Ny. Tidak terdapat peningkata kekuatan otot dikarena kondisi kesadaran samnolen sedangkan Ny.M peningkatan kekuatan otot pada ekstremitas atas menjadi skala 6 dan ekstremitas bawah skala 4 .

5. Evaluasi keperawatan pada Ny.N dimana tidak terdapat peningkatan skala kekuatan otot. Hal ini karena Ny.N keadaannya lebih darurat dan penyakit stroke nya sudah lama dan disertai tingkat kesadaran samnolen. Evaluasi keperawatan secara konferensi pada Ny.N 6 masalah keperawatan yang muncul hanya 2 masalah keperawatan yang teratasi. Sedangkan Ny. M dari 4 masalah keperawatan teratasi semuanya.

\section{Saran}

1. Rumah Sakit

Dapat meningkatkan kualitas pelayanan kesehatan terutama terhadap penderita stroke, meningkatkan upaya pelayanan kesehatan yang lebih utama adalah upaya preventif dan ada jadwal rehabilitasi terpadu yang terinteritas antara perawat, fisioterapi dan keluarga untuk mencegah tidak terjadi kontraktur ataupun atrofi otot. 
2. Institusi Pendidikan

Memberikan waktu yang khusus untuk mahasiswa dengan tidak memberikan waktu yang bersamaan dengan kegiatan perkuliahan lain agar mahasiswa dapat menyusun Laporan Tugas Akhir dengan baik dalam batas waktu yang dibutuhkan.

3. Peneliti selanjutnya

Diharapkan peneliti selanjutnya dalam penerapan asuhan keperawatan Stroke Non Hemoragik dengan gangguan perfusi jaringan serebral dengan penurunan kesadaran pada klien stroke hemoragik setelah diberikan posisi kepala elevasi $30^{\circ}$.

\section{DAFTAR PUSTAKA}

Agusman, Fery \& Evi Kusgiarty.(2017). Pengaruh Mirror Therapy Terhadap Kekuatan Otot Pasien Stroke Non Hemoragik Di RSUD Kota Semarang. Jurnal keperawtan Vol.4 No.1.

Arum. (2015). Panduan Bergambar Tentang Penegahan dan Pemulihan Stroke. Kelompok Gramedia. Jakarta.

Dinas Kesehatan Provinsi Sumatera Selatan. 10 Penyakit Terbesar Di Provinsi Sumatera Selatan. Bank Data Dinkes Provinsi Sumatera Selatan 2017.

Erlita. (2017). Penyakit - Penyakit Mematikan. Yogyakarta: Nuha Medika.

Escardio. 2016. Faktor - Factor yang

Berhubungan dengan Frekuensi

Kekambuhan Stroke. Kelompok Gramedia. Jakarta.

Debora, O. (2011). Proses Keperawatan dan Pemeriksaan Fisik. Jakarta: Salemba Medika.

Junaidi, Iskandar. (2011). Stroke Waspadai Ancamannya. Yogyakarta : Andi Offset.

Jung, Hee Kim, \& Lee Byoung Hee. (2014). Mirror Therapy Combined With Biofeedback Functional Electrical Stimulation for Motor Recovery of
Upper Extremities After Stroke: A Pilot Randomized Controlled Trial. Published online 4 November 2014.

Ghani. (2017). Farmakologi Dalam Neurologis. Salemba Medika : Jakarta.

Harsono.(2015). Kapita Selekta Neurologi. Yogyakarta: Gadjah Mada University Press.

Hopkins, Tracey.(2013). Intisari Medikal Bedah: Buku Praktik Klinik Edisi 3. Jakarta: Kedokteran EGC.

Irawati, Popy, Rita Sekarwati dan Arie Marsita.(2016). Efektivitas Latihan Range Of Motion Cylindrical Grip Terhadap Peningkatan Kekuatan Otot Ekstremitas Atas Pada Pasien Stroke Non Hemoragik Di Ruang Rawat Inap RSU Kabupaten Tangerang. Jakarta, Edisi Nomor 2.

Irfan, Muhammad.(2012).Fisioterapi Bagi Insan Stroke. Yogyakarta: Graha Ilmu, Jakarta: Salemba Medika.

Koes, Irianto. (2015). Beberapa Faktor Penyebab Kejadian Stroke Berulang (Studi Kasus di RS.DR.Kariadi Semarang) Diakses tanggal 11 April 2016 dalam

http://www.eprints.undip.ac.id/49 42.com.

Masriadi. (2016). Pengertian Stroke Non Hemoragik . Jurnal Stroke ,(online)(http://www.psychology mania.com/2012/12/pengertianjenis-kelamin.html, di akses 15 Maret 2016).

Mutaqin, Arif. (2011). Buku ajar asuhan keperawatan klien dengan gangguan sistem persyarfan. Jakarta: Salemba Medika.

NANDA. (2015). Diagnosis Keperawatan Definisi \& Klasifikasi 2015-2017 Edisi. 10 editor $T$ Heather Herdman, Shigemi Kamitsuru. Jakarta: EGC.

Potter and Perry. (2010). Fundamental Of NurshingBuku 3 Edisi. Salemba Medika: Jakarta. 
Riyadi, Sujono.(2015). Kebutuhan Dasar Manusia Aktivitas Istirahat Diagnosis Nanda. Yogyakarta: Gosyen Publishing.

RIKESDAS KEMENKES. (2018). Angka Kejadian Stroke di Indonesia. http://www.depkes.go.id/article/vi ew/201407200001/presidenresmikan-rs-pusat-otaknasional.html

Septiyani. (2017). Panduan Praktis Pencegahan Dan Pengobatan Stroke. Jakarta : Bhuana Ilmu Populer.

Sukmaningrum, Febrina \& Sri Puguh Kristiyawati. (2012). Efektivitas Range Of Motion (ROM) Aktif Asistif : Spherical Grip Terhadap Peningkatan Kekuatan Otot Ekstremitas Atas Pada Pasien Stroke Di RSUD Tugurejo Semarang. Stikes Telogorejo Semarang.

Olviani, Yurida, M \& Indah Rahmawati. 2017. Pengaruh Latihan Range Of Motion (ROM) Aktif - Asistif (Spherical Grip) Terhadap Peningkatan Kekuatan Otot Ekstremitas Atas Pada Pasien Stroke Di Ruang Rawat Inap Penyakit Syaraf ( Seruni) RSUD Ulin Banjarmasin. Dinamika Kesehatan,Vol.8 No. 1.

WHO. 2016. Angka Kejadian Stroke. Diakses tanggal 11 April 2016 dalam

http://repository.wima.ac.id/1234/ 2/Bab\%201.pdf.

Zulaikah, Sri Puguh Kristyawati \& S Eko Ch. (2013). Pengaruh Alih Baring 2 jam terhadap resiko decubitus dengan varian berat badan pasien bedrest total di SMC RS Telogorejo. Skripsi. 